\title{
Disturbance of Temperature Regulation
}

National Cancer Institute

\section{Source}

National Cancer Institute. Disturbance of Temperature Regulation. NCI Thesaurus. Code C121629.

Any condition characterized by an inability to regulate body temperature. 